\title{
CARACTERIZAÇÃO ANATÔMICA MACROSCÓPICA DAS MADEIRAS UTILIZADAS PARA LAMINAÇÃO NA REGIÃO DE CURITIBA-PR
}

\section{ANATOMIC CHARACTERIZATION OF WOOD SPECIES USED IN VENEER PRODUCTION IN CURITIBA-PR}

\author{
Silvana NISGOSKI ${ }^{1}$ \\ Graciela Inés Bolzon de MUÑIZ² \\ Gregório CECCANTINI ${ }^{3}$
}

\begin{abstract}
RESUMO
Este trabalho trata da caracterização anatômica macroscópica das principais madeiras utilizadas para laminação na região de Curitiba-PR. Foram coletadas 72 amostras de lâminas faqueadas e torneadas, sendo avaliadas as características observadas a olho nu ou com lupa conta-fios com aumento de 10x. Foram descritas 25 espécies, e as que apresentaram maior dificuldade de diferenciação foram reunidas em três grupos, de acordo com suas semelhanças em cor, textura e características anatômicas. Pelas observações realizadas neste trabalho conclui-se que é possível a separação entre estas espécies. Para isto, o parênquima axial deve ser a primeira estrutura avaliada, seguida pelos vasos (agrupamento, tamanho, obstrução e porosidade) e os raios, fechando a identificação.
\end{abstract}

Palavras-chave: análise macroscópica, estrutura anatômica, lâminas de madeira.

\begin{abstract}
This work is about anatomic macroscopic characterization of main species used in veneer production in Curitiba, Parana State, Brazil. Seventy-two sliced veneers and rotary cut veneers samples were collected. Evaluation of characteristics observed without lens or with increased ten times lens were described. Twenty-five species were described, and the most similar were grouped by color, texture and anatomic characteristics. Species separation is possible, and the first structure that may be analyzed is axial parenchyma, after vessels and rays.
\end{abstract}

Key-words: macroscopic analysis, anatomic structure, veneer.

\footnotetext{
${ }^{1}$ Eng. Florestal, Msc. Doutoranda UFPR. Bolsista CAPES. Av. Pref. Lothário Meissner, 3400. Jardim Botânico. Campus III da UFPR. $80.210-170$. Curitiba-PR.silnis@yahoo.com;

${ }^{2}$ Eng. Florestal, Profa Dra, Titular, Departamento de Engenharia e Tecnologia Florestal - UFPR

${ }^{3}$ Biólogo, Dr. Universidade de São Paulo. Instituto de Biociências. Departamento de Botânica.
} 
NISGOSKI, S. et al. Caracterização anatômica macroscópica...

\section{INTRODUÇÃO}

No processo de produção das lâminas, as características anatômicas da madeira, influenciam na qualidade final do produto, como, por exemplo, nos desenhos, em problemas ocasionados durante e depois da laminação e no acabamento. Assim sendo, com o conhecimento correto da espécie é possível um maior aproveitamento das toras com a utilização de técnicas adequadas e específicas.

Walker (8) aponta que, para operações de faqueamento, são utilizadas ampla diversidade de espécies. São usadas para produzir lâminas de alto valor e com desenhos para utilizar nas capas de painéis. As lâminas são cortadas muito finas para maximizar a área de corte de madeiras com grandes comprimentos. As características visuais que determinam o valor particular de uma lâmina estão relacionados à cor e figura e à maneira com a qual a tora é faqueada.

O processo de identificação científica de uma amostra de madeira é complexo, envolvendo diversas etapas. O primeiro passo é uma análise da amostra em relação à cor, desenhos e densidade. Depois as superfícies transversal e tangencial devem ser polidas com navalhas para que possam ser visualizadas as características anatômicas, tais como: anéis de crescimento, raios, vasos e parênquima. Deve ser analisada a porosidade, tamanho de raio, presença de estratificação, arranjo dos vasos e arranjo do parênquima. Muitas madeiras são identificadas macroscopicamente, mas outras precisam de análise microscópica para complementar as informações (composição dos raios; presença de células oleíferas; placas de perfuração; pontuações intervasculares; espessamentos; tilos; gomas; cristais; sílica; fibras septadas, etc.) (2).

Até o presente, a maioria dos estudos existentes sobre espécies utilizadas comercialmente estão baseados em madeira serrada $(1,4,5,7,9)$. Isso se deve em parte ao fato da espessura e orientações de corte das lâminas causarem dificuldades de observação das características anatômicas, o que justifica, em parte, a ausência de trabalhos com este material.

O presente trabalho teve como objetivo caracterizar macroscopicamente as lâminas utilizadas na região de Curitiba, visando aprimorar sua correta identificação e fornecer informações da anatomia das espécies amostradas, para serem utilizadas de forma prática, no comércio de lâminas.

\section{MATERIAL E MÉTODOS}

Foram coletadas 72 amostras de lâminas faqueadas e torneadas nas empresas de Curitiba que se dispuseram a fornecer o material. No caso de lâminas faqueadas, cada amostra coletada foi composta por variável número de lâminas cortadas seqüencialmente, ou seja, quando unidas forneciam a imagem da superfície do lenho antes do corte. O nome fornecido pela empresa foi anotado em cada amostra.

As lâminas faqueadas, coletadas seqüencialmente, foram unidas com cola branca até que fosse formado um bloco, de mais ou menos $2,0 \mathrm{x}$ $2,0 \mathrm{~cm}$, de tamanho suficiente para serem analisadas as características macroscópicas do material.

As amostras coletadas nas empresas de Curitiba foram identificadas no Laboratório de Anatomia da Madeira, da Universidade Federal do Paraná (UFPR), sendo confirmadas pelo Laboratório de Produtos Florestais (LPF/DIREN/IBAMA), em Brasília, DF. Para a descrição macroscópica das lâminas, seguiuse as recomendações de Muñiz e Coradin (6), baseadas em lawa (3). Foram analisadas as características visíveis a olho nu e com lupa do tipo conta-fios de aumento $10 x$.

A classificação dos raios foi a seguinte: largos, quando facilmente visíveis a olho nu, semelhantes ao louro-faia, onde atingem $3,0 \mathrm{~mm}$ de largura, no corte transversal; estreitos, algumas vezes visíveis a olho nu, outras não, com no máximo $0,5 \mathrm{~mm}$ de largura; e médios foram considerados aqueles que atingem $0,5-2,0 \mathrm{~mm}$ de largura. Os vasos foram divididos em pequenos, médios e grandes, sendo classificados como pequenos quando, no corte transversal, foram observados como pontos, não sendo possível medir com uma régua comum; grandes, quando estavam próximos a $1 \mathrm{~mm}$ de diâmetro, e médios, com 0,3-0,5 mm de diâmetro.

\section{RESULTADOS E DISCUSSÃO}

Foram descritas as características macroscópicas (visíveis a olho nu ou com lente 10x), observadas nos planos transversal (topo) e tangencial. A identificação foi baseada primeiramente na seção transversal, sendo confirmada posteriormente pela seção tangencial. A face radial não foi descrita uma vez que só é possível a análise detalhada dos raios em microscópio. No caso de cortes que fornecem uma superfície intermediária entre radial e tangencial, devese observar a parte melhor orientada ou tentar, com o auxílio de um canivete, efetuar um pequeno corte na direção correta.

Com os dados das descrições anatômicas macroscópicas, as espécies mais semelhantes entre si foram reunidas em grupos, sendo que as principais características são apresentadas nas Tabelas 1,2,3 e 4.

Na Tabela 1, está o grupo do mogno, reunindo mogno, sapele, cedro, andiroba, jatobá, louro-vermeIho e jequitibá, comercializados como padrão mogno, com coloração avermelhada em diferentes matizes.

No grupo do mogno, os vasos podem apresentar-se como fator de caracterização de algumas espécies, como por exemplo, na separação entre o mogno e o cedro que apresentam, respectivamente, vasos solitários e geminados com 
NISGOSKI, S. et al. Caracterização anatômica macroscópica...

porosidade difusa, e solitários em maioria com porosidade em anel. A diferenciação do mogno e sapele pode ser feita através do tamanho dos vasos (médios e pequenos, respectivamente). A porosidade também pode diferenciar completamen- te o cedro das demais espécies do grupo. Este elemento da anatomia não serve para diferenciar espécies como andiroba, jatobá e louro-vermelho, que por outro lado estão isoladas do mogno, sapele e cedro pelo seu agrupamento característico (solitários e múltiplos).

TABELA 1 - Características anatômicas macroscópicas das madeiras do grupo mogno (padrão mogno) comercializadas na região de Curitiba, PR. Curitiba, 1999.

\begin{tabular}{|c|c|c|c|c|}
\hline & \multicolumn{4}{|c|}{ Características } \\
\hline Espécie & Vasos & Parênquima Axial & Raios & $\begin{array}{l}\text { Camadas de } \\
\text { Crescimento }\end{array}$ \\
\hline $\begin{array}{l}\text { Mogno } \\
\text { (Swietenia sp.) } \\
\text { Meliaceae }\end{array}$ & $\begin{array}{l}\text { solitários e geminados } \\
\text { médios } \\
\text { óleo resina } \\
\text { porosidade difusa }\end{array}$ & faixas marginais & $\begin{array}{l}\text { finos } \\
\text { estratificados }\end{array}$ & $\begin{array}{l}\text { parênquima } \\
\text { marginal }\end{array}$ \\
\hline $\begin{array}{l}\text { Sapele } \\
\text { (Entandrophragma sp.) } \\
\text { Meliaceae }\end{array}$ & $\begin{array}{l}\text { solitários em maioria } \\
\text { pequenos } \\
\text { óleo resina } \\
\text { porosidade difusa }\end{array}$ & faixas marginais & $\begin{array}{l}\text { finos } \\
\text { estratificados }\end{array}$ & $\begin{array}{l}\text { parênquima } \\
\text { marginal }\end{array}$ \\
\hline $\begin{array}{l}\text { Andiroba } \\
\text { (Carapa sp.) } \\
\text { Meliaceae }\end{array}$ & $\begin{array}{l}\text { solitários e múltiplos } \\
\text { pequenos a médios } \\
\text { óleo resina } \\
\text { porosidade difusa }\end{array}$ & faixas marginais & $\begin{array}{l}\text { finos } \\
\text { não estratificados }\end{array}$ & $\begin{array}{l}\text { parênquima } \\
\text { marginal }\end{array}$ \\
\hline $\begin{array}{l}\text { Cedro } \\
\text { (Cedrela sp.) } \\
\text { Meliaceae }\end{array}$ & $\begin{array}{l}\text { solitários em maioria } \\
\text { pequenos e grandes } \\
\text { óleo resina } \\
\text { porosidade em anel }\end{array}$ & faixas marginais & $\begin{array}{l}\text { finos } \\
\text { não estratificados }\end{array}$ & $\begin{array}{l}\text { parênquima } \\
\text { marginal }\end{array}$ \\
\hline $\begin{array}{l}\text { Jequitibá } \\
\text { (Cariniana sp.) } \\
\text { Lecythidaceae }\end{array}$ & $\begin{array}{l}\text { solitários em maioria } \\
\text { pequenos a médios } \\
\text { óleo resina } \\
\text { porosidade difusa }\end{array}$ & reticulado & $\begin{array}{l}\text { finos } \\
\text { não estratificados }\end{array}$ & zonas fibrosas \\
\hline $\begin{array}{l}\text { Louro-vermelho } \\
\text { (Nectandra sp.) } \\
\text { Lauraceae }\end{array}$ & $\begin{array}{l}\text { solitários e múltiplos } \\
\text { pequenos a médios } \\
\text { óleo resina } \\
\text { porosidade difusa }\end{array}$ & indistinto & $\begin{array}{l}\text { finos } \\
\text { não estratificados }\end{array}$ & indistintas \\
\hline $\begin{array}{l}\text { Jatobá } \\
\text { (Hymenaea sp.) } \\
\text { Caesalpiniaceae }\end{array}$ & $\begin{array}{l}\text { solitários e múltiplos } \\
\text { pequenos a médios } \\
\text { óleo resina } \\
\text { porosidade difusa }\end{array}$ & $\begin{array}{l}\text { faixas marginais, } \\
\text { aliforme e vasicêntrico } \\
\text { escasso }\end{array}$ & $\begin{array}{l}\text { finos } \\
\text { não estratificados }\end{array}$ & $\begin{array}{l}\text { parênquima } \\
\text { marginal }\end{array}$ \\
\hline
\end{tabular}

O parênquima axial é um elemento de restrita utilização para diferenciação deste grupo, pois a maioria apresenta faixas marginais. Entretanto, o jatobá, que apresenta faixas marginais, em geral, intercaladas por aliforme e vasicêntrico escasso, o louro, onde é indistinto, e o jequitibá, que apresenta parênquima reticulado, se diferenciam dos demais. Por outro lado, este elemento pode facilmente distinguir a andiroba do jatobá e lourovermelho. A estratificação dos raios é um elemento de grande importância na diferenciação entre mogno e sapele e as demais espécies do grupo. Em alguns casos o mogno não apresenta raios estratificados, sendo necessária e importante a verificação de conteúdo esbranquiçado em seus poros. As camadas de crescimento apresentamse na maioria delimitadas pelo parênquima marginal, não sendo um fator de distinção entre espécies, com exceção do louro-vermelho, que apresenta camadas de crescimento indistintas, e o jequitibá onde é demarcado por zonas fibrosas.

$\mathrm{Na}$ Tabela 2 foram reunidos pau-marfim, marfim-arana, muiratinga, marupá, amapá amargoso e amapá-doce, espécies com cores amareladas, em diferentes matizes. No comércio, fazem parte da denominação padrão marfim. 
NISGOSKI, S. et al. Caracterização anatômica macroscópica...

TABELA2 - Características anatômicas macroscópicas das madeiras do grupo pau marfim (padrão marfim) comercializadas na região de Curitiba, PR. Curitiba, 1999.

\begin{tabular}{|c|c|c|c|c|}
\hline & \multicolumn{4}{|c|}{ Características } \\
\hline Espécie & Vasos & Parênquima Axial & Raios & $\begin{array}{l}\text { Camadas de } \\
\text { Crescimento }\end{array}$ \\
\hline $\begin{array}{l}\text { Pau marfim } \\
\text { (Balfourodendron sp.) } \\
\text { Rutaceae }\end{array}$ & $\begin{array}{l}\text { solitários e múltiplos } \\
\text { muito pequenos } \\
\text { vazios } \\
\text { porosidade difusa }\end{array}$ & faixas marginais & $\begin{array}{l}\text { finos } \\
\text { não estratificados }\end{array}$ & $\begin{array}{l}\text { parênquima } \\
\text { marginal }\end{array}$ \\
\hline $\begin{array}{l}\text { Marfim-arana } \\
\text { (Chrysophyllum sp.) } \\
\text { Sapotaceae }\end{array}$ & $\begin{array}{l}\text { solitários, múltiplos radiais } \\
\text { muito pequenos a pequenos } \\
\text { tilos presentes } \\
\text { porosidade difusa }\end{array}$ & linhas irregulares & $\begin{array}{l}\text { finos } \\
\text { não estratificados }\end{array}$ & $\begin{array}{l}\text { zonas } \\
\text { fibrosas }\end{array}$ \\
\hline $\begin{array}{l}\text { Muiratinga } \\
\text { (Maquira sp.) } \\
\text { Moraceae }\end{array}$ & $\begin{array}{l}\text { solitários em maioria } \\
\text { pequenos a médios } \\
\text { vazios } \\
\text { porosidade difusa }\end{array}$ & $\begin{array}{l}\text { vasicêntrico, aliforme } \\
\text { losangular }\end{array}$ & $\begin{array}{l}\text { finos } \\
\text { não estratificados }\end{array}$ & indistintas \\
\hline $\begin{array}{l}\text { Marupá } \\
\text { (Simarouba sp.) } \\
\text { Simaroubaceae }\end{array}$ & $\begin{array}{l}\text { solitários em maioria } \\
\text { médios } \\
\text { óleo resina presente } \\
\text { porosidade difusa }\end{array}$ & $\begin{array}{l}\text { aliforme linear e } \\
\text { confluente em trechos } \\
\text { curtos e longos }\end{array}$ & $\begin{array}{l}\text { finos } \\
\text { estratificados }\end{array}$ & indistintas \\
\hline $\begin{array}{l}\text { Amapá-amargoso } \\
\text { (Parahancornia sp.) } \\
\text { Apocynaceae }\end{array}$ & $\begin{array}{l}\text { solitários, múltiplos radiais } \\
\text { pequenos } \\
\text { vazios } \\
\text { porosidade difusa }\end{array}$ & linhas irregulares & $\begin{array}{l}\text { finos } \\
\text { não estratificados }\end{array}$ & indistintas \\
\hline $\begin{array}{l}\text { Amapá-doce } \\
\text { (Brosimum sp.) } \\
\text { Moraceae }\end{array}$ & $\begin{array}{l}\text { solitários em maioria } \\
\text { médios a grandes } \\
\text { tilos presentes } \\
\text { porosidade difusa }\end{array}$ & $\begin{array}{l}\text { aliforme linear e } \\
\text { confluente em trechos } \\
\text { curtos }\end{array}$ & $\begin{array}{l}\text { médios } \\
\text { não estratificados }\end{array}$ & $\begin{array}{l}\text { zonas } \\
\text { fibrosas }\end{array}$ \\
\hline
\end{tabular}

No grupo do pau-marfim, os vasos se apresentam vazios ou obstruídos, pela presença de tilos no caso do marfim-arana e amapá-doce, e óleo resina no marupá, fatores que podem distingui-los de outras espécies. O marfim-arana pode se distinguir de todo grupo pela presença de vasos solitários e cadeias radiais. O parênquima axial é diferente em todas as espécies, portanto cada um apresenta a sua especificidade. Os raios finos e estratificados do marupá o distinguem de todo o restante do grupo, que apresentam raios não estratificados. As camadas de crescimento definem algumas espécies deste grupo, como por exemplo, o pau-marfim, que apresenta parênquima marginal delimitando esta estrutura.

O terceiro grupo, formado por curupixá, tauari e jequitibá rosa mostra a grande semelhança entre estas madeiras, sendo sua diferenciação muito difícil, principalmente entre tauari e jequitibá rosa que são vendidos como tauari e tauari vermelho, sem separação (Tabela 3).

TABELA 3 - Características anatômicas macroscópicas das madeiras do grupo tauari comercializadas na região de Curitiba, PR. Curitiba, 1999.

\begin{tabular}{|c|c|c|c|c|}
\hline & \multicolumn{4}{|c|}{ Características } \\
\hline Espécie & Vasos & Parênquima Axial & Raios & $\begin{array}{l}\text { Camadas de } \\
\text { Crescimento }\end{array}$ \\
\hline $\begin{array}{l}\text { Tauari } \\
\text { (Couratari spp.) } \\
\text { Lecythidaceae }\end{array}$ & $\begin{array}{l}\text { solitários e múltiplos até } 4 \\
\text { pequenos a médios } \\
\text { vazios } \\
\text { porosidade difusa }\end{array}$ & reticulado & $\begin{array}{l}\text { finos } \\
\text { não estratificados }\end{array}$ & $\begin{array}{l}\text { zonas } \\
\text { fibrosas }\end{array}$ \\
\hline $\begin{array}{l}\text { Jequitibá-rosa } \\
\text { (Cariniana micrantha) } \\
\text { Lecythidaceae }\end{array}$ & $\begin{array}{l}\text { solitários e múltiplos } \\
\text { médios } \\
\text { vazios } \\
\text { porosidade difusa }\end{array}$ & reticulado & $\begin{array}{l}\text { finos a médios } \\
\text { não estratificados }\end{array}$ & $\begin{array}{l}\text { afastamento } \\
\text { poros e linhas } \\
\text { de } \\
\text { parênquima }\end{array}$ \\
\hline $\begin{array}{l}\text { Curupixá } \\
\text { (Micropholis spp.) } \\
\text { Sapotaceae }\end{array}$ & $\begin{array}{l}\text { solitários e múltiplos radiais } \\
\text { pequenos a médios } \\
\text { substância esbranquiçada } \\
\text { porosidade difusa }\end{array}$ & $\begin{array}{l}\text { retículo irregular com } \\
\text { os raios }\end{array}$ & $\begin{array}{l}\text { finos } \\
\text { não estratificados }\end{array}$ & $\begin{array}{l}\text { afastamento } \\
\text { das linhas de } \\
\text { parênquima }\end{array}$ \\
\hline
\end{tabular}


NISGOSKI, S. et al. Caracterização anatômica macroscópica...

No caso das amostras coletadas, pequenas variações foram observadas, o que nem sempre ocorre. A obstrução dos poros por substância esbranquiçada pode se apresentar como elemento de distinção no curupixá. O parênquima axial, raios e camadas de crescimento, não se apresentam como elementos de grande valia para a distinção entre es- tas espécies, uma vez que são muito semelhantes.

O restante das espécies (amescla, carvalho, cerejeira, eucalipto, freijó, goiabão, imbuia, louro-faia, pau-ferro, sucupira), que apresentam características distintas, não foram agrupados, uma vez que não foram observados erros na identificação e comercialização (Tabela 4).

TABELA 4 - Principais características anatômicas macroscópicas das outras espécies comercializadas na região de Curitiba, PR. Curitiba, 1999.

\begin{tabular}{|c|c|c|c|c|c|}
\hline & \multicolumn{5}{|c|}{ Características } \\
\hline Espécie & Vasos & & Parênquima Axial & Raios & $\begin{array}{l}\text { Camadas de } \\
\text { Crescimento }\end{array}$ \\
\hline $\begin{array}{l}\text { Amescla } \\
\text { (Trattinickia burseraefolia) } \\
\text { Burseraceae }\end{array}$ & $\begin{array}{l}\text { solitários e múltiplos } \\
\text { pequenos } \\
\text { tilos presentes } \\
\text { porosidade difusa }\end{array}$ & & indistinto & $\begin{array}{l}\text { finos } \\
\text { não estratificados }\end{array}$ & zonas fibrosas \\
\hline $\begin{array}{l}\text { Carvalho } \\
\text { (Quercus spp.) } \\
\text { Fagaceae }\end{array}$ & $\begin{array}{l}\text { solitários em maioria } \\
\text { pequenos e grandes } \\
\text { tilos presentes } \\
\text { porosidade em anel }\end{array}$ & & faixas sinuosas & $\begin{array}{l}\text { médios a largos } \\
\text { não estratificados }\end{array}$ & $\begin{array}{l}\text { porosidade em } \\
\text { anel }\end{array}$ \\
\hline $\begin{array}{l}\text { Cerejeira } \\
\text { (Amburana cearensis) } \\
\text { Fabaceae }\end{array}$ & $\begin{array}{l}\text { solitários em maioria } \\
\text { médios a grandes } \\
\text { óleo resina } \\
\text { porosidade difusa }\end{array}$ & & $\begin{array}{lr}\text { vasicêntrico, } & \\
\text { aliforme } & \mathrm{e} \\
\text { confluente } & \text { em } \\
\text { trechos curtos } & \\
\end{array}$ & $\begin{array}{l}\text { médios finos } \\
\text { estratificação } \\
\text { irregular }\end{array}$ & indistinta \\
\hline $\begin{array}{l}\text { Eucalipto } \\
\text { (Eucalyptus spp.) } \\
\text { Myrtaceae }\end{array}$ & $\begin{array}{l}\text { solitários em maioria } \\
\text { pequenos } \\
\text { tilos presentes } \\
\text { porosidade difusa }\end{array}$ & & $\begin{array}{l}\text { vasicêntrico } \\
\text { confluente }\end{array}$ & $\begin{array}{l}\text { finos } \\
\text { não estratificados }\end{array}$ & indistintas \\
\hline $\begin{array}{l}\text { Freijó } \\
\text { (Cordia goeldiana) } \\
\text { Boraginaceae }\end{array}$ & $\begin{array}{l}\text { solitários em maioria } \\
\text { pequenos a médios } \\
\text { tilos presentes } \\
\text { porosidade difusa }\end{array}$ & & $\begin{array}{l}\text { vasicêntrico } \\
\text { aliforme }\end{array}$ & $\begin{array}{l}\text { médios } \\
\text { não estratificados }\end{array}$ & zonas fibrosas \\
\hline $\begin{array}{l}\text { Goiabão } \\
\text { (Pouteria pachycarpa) } \\
\text { Sapotaceae }\end{array}$ & $\begin{array}{l}\text { cadeias radiais } \\
\text { muito pequenos } \\
\text { pequenos } \\
\text { tilos presentes } \\
\text { porosidade difusa }\end{array}$ & a & $\begin{array}{l}\text { faixas } \\
\text { irregularmente } \\
\text { espaçadas }\end{array}$ & $\begin{array}{l}\text { finos } \\
\text { não estratificados }\end{array}$ & $\begin{array}{l}\text { indistintas ou } \\
\text { afastamento } \\
\text { linhas de } \\
\text { parênquima }\end{array}$ \\
\hline $\begin{array}{l}\text { Imbuia } \\
\text { (Ocotea porosa) } \\
\text { Lauraceae }\end{array}$ & $\begin{array}{l}\text { solitários em maioria } \\
\text { pequenos } \\
\text { óleo resina } \\
\text { porosidade difusa }\end{array}$ & & vasicêntrico & $\begin{array}{l}\text { finos } \\
\text { não estratificados }\end{array}$ & zonas fibrosas \\
\hline $\begin{array}{l}\text { Louro-faia } \\
\text { (Euplassa spp.) } \\
\text { Proteaceae }\end{array}$ & $\begin{array}{l}\text { solitários e múltiplos } \\
\text { pequenos a médios } \\
\text { conteúdo escuro } \\
\text { porosidade difusa }\end{array}$ & & $\begin{array}{l}\text { linhas finas, } \\
\text { formando arcos } \\
\text { entre os raios }\end{array}$ & $\begin{array}{l}\text { muito largos } \\
\text { não estratificados }\end{array}$ & indistintas \\
\hline $\begin{array}{l}\text { Pau-ferro } \\
\text { (Machaerium scleroxylon) } \\
\text { Fabaceae }\end{array}$ & $\begin{array}{l}\text { solitários em maioria } \\
\text { muito pequenos } \\
\text { pequenos } \\
\text { vazios } \\
\text { porosidade difusa }\end{array}$ & $a$ & $\begin{array}{lr}\text { vasicêntrico } & \mathrm{e} \\
\text { aliforme losangular }\end{array}$ & $\begin{array}{l}\text { finos a médios } \\
\text { não estratificados }\end{array}$ & $\begin{array}{l}\text { zonas fibrosas } \\
\text { e finas linhas } \\
\text { de parênquima } \\
\text { marginal }\end{array}$ \\
\hline $\begin{array}{l}\text { Sucupira } \\
\text { (Bowdichia nitida) } \\
\text { Fabaceae }\end{array}$ & $\begin{array}{l}\text { solitários em maioria } \\
\text { médios } \\
\text { óleo resina } \\
\text { porosidade difusa }\end{array}$ & & $\begin{array}{l}\text { vasicêntrico, } \\
\text { aliforme } \\
\text { confluente }\end{array}$ & $\begin{array}{l}\text { finos a médios } \\
\text { estratificados }\end{array}$ & indistintas \\
\hline
\end{tabular}


Características diagnósticas

Com base nos resultados obtidos neste trabaIho, consideram-se os seguintes pontos como os mais importantes e significantes na identificação macroscópica de lâminas das espécies pesquisadas neste trabalho:

1) No grupo do mogno, avaliando-se inicialmente o parênquima axial, e depois os raios e vasos, pode-se identificar algumas espécies: reticulado

- o jequitibá é o único com parênquima axial

- o louro-vermelho pode ser identificado por apresentar parênquima axial e camadas de crescimento indistintas;

- o jatobá pode se diferenciar pelo maior número de faixas de parênquima axial, intercalado por aliforme e vasicêntrico escasso;

- o cedro pode ser identificado por ser o único com porosidade em anel do grupo;

- a andiroba pode ser identificada e distinguida do mogno e sapele por apresentar raios não estratificados;

- o mogno e o sapele, que apresentam características anatômicas semelhantes, podem ser distinguidos um do outro pelo tamanho dos poros, onde o mogno apresenta poros maiores;

2) No grupo do pau-marfim, algumas características que podem identificar e distinguir espécies são enumeradas a seguir:

- o pau-marfim pode ser identificado por apresentar parênquima axial em faixas marginais e camadas de crescimento delimitadas por esta estrutura;

- marupá e amapá-doce apresentam parênquima axial aliforme de extensão linear e confluente em trechos curtos, sendo diferenciados pela presença de estratificação dos raios no marupá;
- Amapá amargoso e marfim-arana apresentam poros múltiplos radiais, sendo diferenciados pela presença de cadeias radiais de até seis poros no marfim-arana, enquanto no amapá amargoso a grande maioria é de dois a três poros; muiratinga apresenta parênquima vasicêntrico e aliforme losangular, de extensão muito curta e poros solitários em maioria;

3) No grupo do tauari, de espécies muito semelhantes anatomicamente, a separação macroscópica é muito difícil, e mesmo que pequenas características sejam observadas, recomenda-se a análise microscópica do material.

\section{CONCLUSÕES}

Pelas amostras e características analisadas neste trabalho, conclui-se que: é possível a correta identificação de amostras de madeira laminada; as madeiras laminadas são melhor identificadas se recoladas para a formação de um bloco e que para a separação entre as espécies as características anatômicas mais úteis são o parênquima axial, que deve ser estudado primeiro, seguido pelos vasos (agrupamento, tamanho, obstrução e porosidade) e os raios, fechando a identificação.

\section{AGRADECIMENTOS}

À CAPES, pela concessão da bolsa de Mestrado à primeira autora e às empresas de laminação da região de Curitiba pelo fornecimento do material, sem o qual este trabalho não seria possível.

\section{REFERÊNCIAS BIBLIOGRÁFICAS}

1. ABPM. Perfil de consumo de produtos de madeira; processamento mecânico. São Paulo: ABPM, 1989. 32p.

2. CORE, H.A.; CÔTÉ, W.A. \& DAY, A.C. Wood structure and identification. USA: Syracuse University Press, 1979. 182p.

IAWA. List of microscopic features for hardwood identification. IAWA Bulletin. Vol. 10(3), 1989. p.219-332.

4. IBDF. Identificação e agrupamento de espécies de madeiras tropicais amazônicas; síntese. Brasília: IBDF, 1985. $59 p$

5. IPT. Identificação de espécies de madeira. São Paulo: IPT, 1993. 34p. (Relatório n³1.832).

6. MUÑIZ, GIB. \& CORADIN, VR. Normas de procedimentos em estudos de anatomia da madeira: I-Angiospermae, IIGimnospermae. Brasília: Laboratório de Produtos Florestais, Série Técnica 15, 1991.

7. OZÓRIO FILHO, HL. \& ALFONSO, VA. Identificação anatômica das madeiras utilizadas na Cidade de São Paulo (Relatório Parcial). Instituto de Biociências-USP. 1995.

8. WALKER, JCF. et alli. Primary wood processing: principles and practice. London: Chapman \& Hall, 1993. 595p.

9. ZENID, GJ. Identificação e grupamento das madeiras serradas empregadas na construção civil habitacional na cidade de São Paulo. São Paulo, 1997, 170f. Dissertação (Mestrado em Ciência e Tecnologia de Madeiras). Universidade de São Paulo. 